\title{
Burnout Syndrome in Medical Students in the Kingdom of Bahrain
}

\author{
Basem Abbas Al Ubaidi ${ }^{1}$, Ghufran Jassim ${ }^{2}$ \& Abdelhalim Salem ${ }^{3}$ \\ ${ }^{1}$ Ministry of health, Manama, Bahrain \\ ${ }^{2}$ Royal College of Surgeons in Ireland Medical University of Bahrain, Busaiteen, Bahrain \\ ${ }^{3}$ Arabian Gulf University, Manama, Bahrain \\ Correspondence: Ghufran Jassim, Family Medicine Department, School of Medicine, Royal College of Surgeons \\ in Ireland Medical University of Bahrain, Busaiteen, Bahrain. Tel: 973-17-351-450. E-mail: \\ gjassim@rcsi-mub.com
}

Received: August 8, 2018 Accepted: September 17, 2018 Online Published: October 13, 2018

doi:10.5539/gjhs.v10n11p86

URL: https://doi.org/10.5539/gjhs.v10n11p86

\begin{abstract}
Objectives: To assess stress and burnout, and identify common stressors, among medical students in the Kingdom of Bahrain.

Study Design: A cross-sectional study with students being evaluated from March to September 2017 at two medical colleges in the Kingdom of Bahrain.

Methodology: Survey conducted on a total sample of 533 clerkship-training students with a total of 347 respondents. The instruments used were Cohen's Perceived Stress Scale; the Maslach Burnout Inventory; and a common stressors questionnaire.
\end{abstract}

Results: $65 \%$ (347/533) of the students from the two medical colleges responded to the questionnaire. It was found that the mean (SD) of Cohen stress score in this study was 21.76 (5.60), with a stress and burnout prevalence of $47 \%$ and $43.43 \%$ respectively. A high percentage of respondent students $(68 \%)$ also exhibited high emotional exhaustion scores $>14$. More than half of the respondents (53.3\%) exhibited high cynicism score $>6$. Statistically significant differences were observed across gender categories with Cohen mean score, emotional exhaustion and cynicism. Multiple linear regressions revealed gender to be the only statistically significant predictor of the Cohen score (p. value 0.042).

Conclusion: Clerkship medical students displayed high levels of both stress and burnout prevalence. Medical educators must be aware of the early signs, causes and consequences of student stress. They should also be able to encourage students to improve their mental and physical health, promote mental well-being and teach stress management.

Keywords: burnout syndrome, anxiety, medical students, clerkship training, emotional exhaustion, Bahrain

\section{Introduction}

Stress is characterized as mental and/or physical tension with the presence of intense feelings of worry and anxiety. Stress is associated with patients' ill responses and/or ineffective coping mechanisms towards a range of stressors, which could negatively impact their overall psychological, physical and social wellbeing (Seo et al., 2015; Fares et al., 2016; Siddiqui 2016; Sreedevi et al., 2016; Konjengbam, 2015). Chronic exposure to emotional stress which is especially exasperated in highly demanding environments could eventually lead to burnout; burnout triggers conditions such as depression, insomnia, feelings of detachment and/or fatigue, as well as excessive anxiety over future concerns (Seo et al., 2015; Fares et al., 2016; Siddiqui, 2016; Sreedevi et al., 2016; Konjengbam, 2015). At its worst, excessive stress could lead to suicide ideation or even suicidal attempts (Dafaalla, 2016).

Medical students in specific are predisposed to extraordinary levels of stress and/or burnout due to the remarkably challenging set of stressors they are exposed to, ranging from highly demanding and competitive medical learning processes to complex curriculums, repetitive exams and heavy stressful academic pressure(s) (Seo et al., 2015; Fares et al., 2016). Students are expected to also juggle their personal and daily practical issues within a state of constant scarce and limited social time. Such issues may include studying away from home, high parental expectations, economic worries and/or familial issues. Additional stressors encountered explicitly during the clinical period of medical education can comprise of a mix of uncertainty, intense clinical anxiety frequents 
requirements to prepare or complete academic tasks and exams, and perhaps with even fear from applying theory into practice (Seo et al., 2015; Fares et al., 2016).

High rates of stress and burnout among medical students are linked to negative effects on their overall educational performance and empathetic competencies, possibly even affecting their future performance as practitioners. Symptoms of stress and burnout among students include emotional exhaustion (from great educational needs), cynicism or academic dishonesty (careless and an apathetic attitude toward educational activities) and low professional efficacy (perception of incompetence) (Konjengbam, 2015). Stress or burnout can also trigger negative personality traits such as depression, neuroticism, obsessiveness, meticulous perfectionism, self-exigency and over-competitiveness (Seo et al., 2015; Fares et al., 2016; Dafaalla, 2016; De Oliva Costa et al., 2012; Kulsoom, 2015). Literature shows that medical training can become toxic when stress or burnout is aggravated by ineffective coping techniques, such as substance abuse issues, unhealthy or morbid lifestyle habits and/or decrease in physical activities (Seo et al., 2015; Fares et al., 2016; Dafaalla, 2016; De Oliva Costa et al., 2012; Kulsoom, 2015).

Studies capture varying degrees of perceived levels of stress suffered by medical students at Arab colleges, and its effects on their academic performance, such as Sudan, (50\%), Egypt (60\%), and Saudi Arabia, ranging from 53\%-72\% respectively (Dafaalla, 2016; Abdelrahman et al., 2013; Abdelghani et al., 2011; Paro et al., 2014). On the other hand, the prevalence of burnout syndrome is reportedly $10 \%$ to $45 \%$, depending on the instrument used for diagnosis (Galan et al., 2014; Youssef, 2016; Ishak et al., 2013; Almeida, 2016; Chigerwe, 2014; Fawzy, 2017). Although low levels of exposure to stress can positively benefit students' performance and improve their academic dynamic (Heinen, 2017; Ludwig et al., 2015), yet it can have unfavourable effects on student outcomes when an imbalance occurs from such pressures, responsibilities and demands ( Ibrahim et al., 2013; Cecil, 2014; Muzafar et al., 2015). Although stress is inevitable, yet burnout is preventable. Therefore, identifying stress among students early during their pre-clinical or training years would help prevent stress and/or burn, and perhaps even affect the long-term quality of their patient care (Sreedevi et al., 2016; Konjengbam, 2015). Stress and burnout are endemic in multi-medical institutions and are usually exhibited early during the preclinical stage, ranging from $62-75 \%$; whereas stress and burnout during the clinical stage range from $25.6-78 \%$ and $10-45 \%$, depending on the instrument used for diagnosis (Galan et al., 2014; Youssef, 2016; Ishak et al., 2013). Regardless, only a few medical schools have already implemented mental well-being programs to support students during their clinical training periods, allowing them to graduate as healthy young physicians (Galan et al., 2014; Youssef, 2016; Ishak et al., 2013; Almeida, 2016; Chigerwe, 2014; Fawzy, 2017; Sohail, 2013).

The primary objective is to assess the level(s) of stress and burnout and their predictors at two main medical colleges at the Kingdom of Bahrain, namely the College of Medicine and the Medical Science at Arabian Gulf University (AGU) and the Medical University of Bahrain at Royal College of Surgeons in Ireland (RCSI Bahrain). Both universities belong to unique didactic backgrounds and socioeconomic conditions. Since 1981, AGU has been offering a four-year BSc degree in medicine, with problem-based learning, with students usually undertaking a $5^{\text {th }}$ and $6^{\text {th }}$ clerkship years. On the other hand, RCSI Bahrain has been providing a five-year MBChB degree since 2004 which offers traditional blended training after the student's first two years.

There has been no previous study done to measure the perceived stress and burnout levels of clinical medical undergraduate students at the Kingdom of Bahrain. This study aims to support mentors and institutional representatives by gathering data and setting a baseline which will ultimately support planning of preventative strategies that will enhance the well-being of students by improving their resilience measures.

This study considers the role of what it classifies as potential adverse stressors among students; namely their academic level, gender, accommodation and marital status. As illustrated above, it is essential for medical instructors to be able to identify stress and burnout at an early stage as it could have detrimental effects on the students' overall well-being, academic performance and future career.

Stress and burnout have remarkable effects on the student's educational performance, psychosocial status and health-related issues. The stressors that fuel the students' stress also affect their mental competences, educational process and academic journey (Dyrbye, 2015; Eva et al., 2015; Al Ubaidi, 2015).

\section{Methods}

This is a cross-sectional study using a self-administered questionnaire which was distributed and collected during a teaching session on students at two medical colleges in the Kingdom of Bahrain: Arabian Gulf University (AGU) and the Royal College of Surgeons in Ireland-Medical University of Bahrain (RCSI Bahrain). This survey took place between March to September 2017, a month before the examination period to minimise significant adverse 
stress symptoms. This study was approved by both AGU's and RCSI's research ethical committees with the consenting students participating guaranteed full confidentiality and privacy.

We approached all clerkship students (533 students). The effort was made to contact non-responding students with a second questionnaire distribution in April-2017. The survey consisted of four separate and validated tools used to assess stress.

The first part of the survey gathered data on the student's socio-demographic characteristics. The second section was composed of 18 questions evaluating every-day stressors primarily related to clinical training. Each question was a 6-point Likert-type scale where the scale ranges from 0 (never) to 6 (every day) (Gazzaz et al., 2018; Al-masry et al., 2013). The common stressors were divided into three domains: relationship problems (4 questions), hospital problems (5 questions) and professional issues (9 questions) (Gazzaz et al., 2018; Al-masry et al., 2013). The third section consisted of 10 questions using the Cohen's Perceived Stress Scale where each question ranges from 0 (never) to 4 (very often) (Gazzaz et al., 2018; Al-masry et al., 2013).

Finally, the last section was the makeup of 15 questions using the Maslach Burnout Inventory-Student Survey, which measures burnout among medical students. It includes emotional exhaustion (5 questions), cynicism (4 questions), and professional efficacy (6 questions). Each item was measured using a 7 point Likert scale ranging from 0 (never) to 6 (every day) (De Oliva Costa et al., 2012).

Each instrument has been previously used in the English language in Saudi Arabia and was shown to be valid among Arab medical students (Abdelghani et al., 2011; Paro et al., 2014; Ibrahim et al., 2013; Schaufeli et al. 2001).

The Cronbach's coefficient of internal consistency was reported to be 0.921 .The data was analysed using SPSS (Statistical Package for Social Sciences, version 22 SPSS Software, SPSS Inc., Chicago, USA).

Descriptive analysis was performed for the socio-demographic characteristics of participants. The mean score of each instrument and its subscales was calculated. This mean was used to test the association between stress and burnout with socio-demographic variables using the $t$-test for independent samples. Mann Whitney test was used instead if the assumption of normality was violated. $\mathrm{P} \leq 0.05$ was set to be statistically significant.

Multiple linear regression tests were implemented to predict the independent variable and Cohen score based on the independent variables.

\section{Results}

The response rate in our study was $65 \%$ (347/533) of the students from the two medical colleges. The mean (SD) age was 22.16 (5.32), with 170/347 (49\%) students undertaking their first clerkship year and 177/347 (51\%) taking their second clerkship year. Forty percent of the students were from the Kingdom of Bahrain with only 21/347 students (6.1\%) being married. Males represented $40.6 \%$, whereas females represented $59.4 \%$ of the sample's population.

One hundred and eighty-three students (52.7\%) were residing in various forms of hostels (without their families). Few students engaged in substance abuse with 75 students are current smoking (21.6\%), 28 students consuming alcohol (8.1\%) and 19 students using illicit drugs (5.5\%).

Table 1. Some socio-demographic characteristics of medical students participants $(N=347)$ in each different study year of clinical training

\begin{tabular}{lll}
\hline Variable & $n(\%)$ & Mean (SD) \\
\hline Sex & $141(40.6)$ & \\
Male & $206(59.4)$ & \\
Female & \\
\hline Academic level & $170(49.0)$ \\
The first year of clerkship & $177(51.0)$ \\
The second year of clerkship & \\
\hline Marital Status & $326(93.9)$ \\
Single & $21(6.1)$ & \\
Married &
\end{tabular}




\begin{tabular}{|c|c|c|}
\hline Accommodation & & \\
\hline With family & $163(47.0)$ & \\
\hline Without family & $183(52.7)$ & \\
\hline Smoking & & \\
\hline Yes & $75(21.6)$ & \\
\hline No & $271(78.1)$ & \\
\hline Consuming alcohol & & \\
\hline Yes & $28(8.1)$ & \\
\hline No & $319(91.9)$ & \\
\hline Using illicit drugs & & \\
\hline Yes & $19(5.5)$ & \\
\hline No & $328(94.5)$ & \\
\hline Exercise & & \\
\hline Yes & $200(57.6)$ & \\
\hline No & $147(42.4)$ & \\
\hline Age (yr) & & $22.16(5.32)$ \\
\hline Hours of sleep at night & & $6.38(1.79)$ \\
\hline Exercise sessions per week & & $2.53(2.02)$ \\
\hline Duration of exercise (minutes per session) & & $37.12(30.79)$ \\
\hline Years exercising & & $2.81(3.72)$ \\
\hline
\end{tabular}

It was found that the mean (SD) of Cohen stress score in this study was $21.76(5.60)$, with a stress and burnout prevalence of $47 \%$ and $43.43 \%$ respectively. A high percentage of respondent students $(68 \%)$ also exhibited high emotional exhaustion scores $>14$. More than half of the respondents (53.3\%) exhibited high cynicism score $>6$. However, the majority of student respondents (91\%) revealed high levels of professional efficiency.

Table 2. Mean scores for the stress, burnout syndrome and common stressors subscales scores $(\mathrm{N}=347)$.

\begin{tabular}{ll}
\hline Instrument & Mean (SD) \\
\hline Cohen Score $^{1}$ & $21.76(5.60)$ \\
\hline Maslach Score $^{-} \quad$ Emotional exhaustion $^{2}$ & $20.12(6.57)$ \\
- Cynicism & \\
- Professional efficiency $^{4}$ & $8.93(2.87)$ \\
\hline
\end{tabular}

Common stressors in clinical training

- Relationship problems

- Professional problems

- Personal problems

\footnotetext{
${ }^{1}$ A Cohen score around 13 is considered average. Scores of 20 or higher indicate high stress.

${ }^{2}$ Emotional exhaustion is either low (0-9 score), moderate (10-14 score) or high (score > 14).

${ }^{3}$ Cynicism is either low (0-1 score), moderate (2-6 score) or high (score $>6$ )

${ }^{4}$ Professional efficiency is either low (score $\left.>27\right)$, moderate $(23-27$ score) or high ( score $<23)$.
}

The study showed a statistically significant difference in the Cohen stress score between sex categories with the 
$p$-value being 0.001 . Likewise, there was a statistically significant difference between emotional exhaustion mean scores among sex categories, with the $p$-value being 0.022 . Furthermore, there was a statistically significant difference between sex categories when looking at both cynicism and relationship problems, with the $p$-value being 0.011 and 0.005 respectively. On the other hand, none of the differences in mean scores reached statistical significance across categories of academic level (Table 3).

Table 3. The association between stress and burnout mean differences in relation to Gender categories (Results of Mann Whitney test)

\begin{tabular}{llll}
\hline Sex & & & \\
\hline Instrument & Male & Female & $p$-value \\
& Mean (SD) & Mean (SD) & 0.001 \\
\hline Cohen Score & $20.57(5.23)$ & $22.58(5.71)$ & 0.022 \\
Emotional exhaustion & $18.98(6.95)$ & $20.89(6.21)$ & 0.011 \\
Cynicism & $8.41(2.83)$ & $9.29(2.85)$ & 0.098 \\
Professional efficiency & $10.63(3.07)$ & $9.99(3.35)$ & 0.005 \\
Relationship problems & $7.63(4.77)$ & $6.29(4.60)$ & 0.176 \\
Professional problems & $10.52(5.94)$ & $11.39(5.66)$ & 0.323 \\
Personal problems & $19.21(10.14)$ & $20.29(10.16)$ & \\
\hline
\end{tabular}

*T-test is used.

Table 4. The association between stress and burnout mean differences across categories of clerkship levels*(Results of Mann Whitney test)

\begin{tabular}{llll}
\hline Clerkship Level & & & \\
\hline Instrument & $\mathbf{1}^{\text {st }}$ clerkship year & $\mathbf{2}^{\text {nd }}$ clerkship year & $\boldsymbol{p}$-value \\
\hline Cohen Score & $21.88(5.53)$ & $21.64(5.67)$ & 0.437 \\
Emotional exhaustion & $19.60(6.79)$ & $20.62(6.34)$ & 0.260 \\
Cynicism & $8.92(2.81)$ & $8.93(2.93)$ & 0.919 \\
Professional efficiency & $10.20(3.30)$ & $10.30(3.21)$ & 0.439 \\
Relationship problems & $6.88(4.95)$ & $6.80(4.49)$ & 0.915 \\
Professional problems & $11.46(6.14)$ & $10.63(5.40)$ & 0.164 \\
Personal problems & $19.98(10.04)$ & $19.73(10.28)$ & 0.656 \\
\hline
\end{tabular}

*Mann-Whitney test used.

On the other hand, the multiple logistic linear regression analysis revealed a considerable amount of variance in the Cohen score $\left(\mathrm{F}(4,336)=2.479, p=0.044 ; \mathrm{R}^{2}=0.029 ; \mathrm{R}^{2}{ }_{\text {Adjusted }}=0.017\right.$ in relation with sex (Standardised Coefficient $=0.11 ; \mathrm{t}(336)=2.04, p=0.042)$. 
Table 5. Multiple linear regression analysis for the Cohen score.

\begin{tabular}{llll}
\hline Predictor (variables) & Standardised Coefficient (Beta) & $\mathbf{t}$ & $\boldsymbol{p}$-value \\
\hline Constant & & 7.17 & \\
Sex & 0.11 & 2.04 & 0.042 \\
$1=$ Male & & & \\
$2=$ Female & & -1.51 & 0.131 \\
\hline Academic level & -0.08 & & \\
$\begin{array}{l}1=1^{\text {st }} \text { year clerkship } \\
2=2^{\text {nd }} \text { year clerkship }\end{array}$ & & & \\
\hline Marital status & 0.08 & 1.59 & 0.112 \\
$1=$ Sigle & & & \\
$2=$ Married & & & \\
\hline $\begin{array}{l}\text { Accommodations } \\
0=\text { away from family }\end{array}$ & -0.01 & -0.34 & 0.731 \\
$1=$ with family & & & \\
\hline
\end{tabular}

\section{Discussion}

Most medical students are eager for the opportunity of having clinical training in hospitals. However, clinical training can be a challenging process as students finally put their theory into practice (Eva et al., 2015; Fares, 2015).

Stress during the training periods can be caused by various factors such as threatening physical environments, demanding instructive methods, embarrassing student-teacher interactions or an unhealthy training atmosphere (Eva et al., 2015; Fares, 2015).

Burnout syndrome among clerkship students occurs when the students begin interacting with patients. During that time, the student is undergoing a time of transition, which is filled with uncertainty and more significant responsibilities (Eva et al., 2015; Fares, 2015).

It is essential for health educators to diagnose stress and burnout among their students and to recognise common stressors in clinical training. Healthcare educators can also build on this data further to make the appropriate changes that will benefit new students and also enhance the skills of new mentors in academic clinical training (Abdelrahman et al., 2013; Abdelghani et al., 2011; Paro et al., 2014; Fawsy, 2017; El-masry, 2013).

The nature of the top stressor in our result was consistent with other studies; there was a substantial difference in the type of the stressor between sex differences in clerkship training year. The explanation for the remarkable stressor, emotional exhaustion and cynicism difference in female student's population are due to higher cultural pressure with less social exposure in medical clerkship training period (Abdelrahman et al., 2013; Abdelghani et al., 2011; Paro et al., 2014; Fawsy, 2017; El-masry, 2013). Moreover, females may be more sensitive than males when dealing with specific types of patients, such as dying patients, severely traumatised patients, patients suffering from severe pain and psychiatric patients (Abdelrahman et al., 2013; Abdelghani et al., 2011; Paro et al., 2014; Fawsy, 2017; El-masry, 2013).

This study showed comparable levels of stress, burnout syndrome and emotional exhaustion among clerkship students in other parts of the world (Abdelrahman et al., 2013; Abdelghani et al., 2011; Paro et al., 2014; Fawsy 2017; El-masry, 2013; Almalki et al., 2017; Chunming et al., 2017; Boni et al., 2018).

The prevalence rate of stress in our study was lower than in Kingdom of Saudi Arabia's colleges. The prevalence rate of stress varied in different countries because of the diverse instrumental measures and different scoring scales used such as (El-masry, 2013; Fares, 2015; Solanky, 2012; Pagnin, 2015; Supe, 1998; Ghandan, 2017).

There was a relatively high proportion of respondent students were suffering from a high burnout level in comparison to other studies (Bera et al., 2013; Vinod et al., 2016; Pagnin, 2015; El Masry et al., 2013; Muzafar et al., 2015).

The explanation for the burnout difference in different countries may be attributed to the variations in the study's 
design, population and instruments used (Muzafar et al., 2015; El-masry, 2013; Pagnin, 2015; Bera et al., 2013; Vinod et al., 2016).

Not surprisingly, as the study showed, whenever there is a highly stressful environment, burnout and emotional exhaustion will flourish.

We found emotional exhaustion to be significantly higher among students who were female and surprisingly, female students living with their families. This could be due to the stronger emotional expressivity of female students with high parent expectations (Niemi, 2006; Guthrie et al., 1998; Bianchin, 2012).

A regression analysis was conducted which showed that gender was the single independent risk factor of the Cohen scores, while other demographic factors were not related (academic clerkship year, marital status, type of accommodation) (El-masry et al., 2013)

The design of the study, limited average response rate, recall bias and social acceptability bias may have played a role in the study's limitation. Also, the study design could not establish a causal relationship among associations. However, despite some limitations, the study proved the need for mental and psychological support systems for clerkship training students.

\section{Conclusion}

Stress, burnout and emotional exhaustion were more evident in medical students in their later clinical training years. The female gender had a high proportion of noticeable results. These findings shed light on the need for a robust system that prevents stress and burnout among these students. This is an essential issue because higher stress and burnout affects the student's education and ultimately impacts their future patients' health.

Medical educators must be aware of the early signs, causes and consequences of student stress. They should also be able to encourage students to improve their mental and physical health, promote mental well-being and teach stress management. Finally, medical colleges should create a nurturing learning environment that identifies and assist struggling students.

\section{Acknowledgements}

The authors thank all of the students who participated in this study for their valuable time participating in the questionnaires distribution: Yusuf M. H. AlAwadhi, Khalifa A. Yusuf, Bano L. Alsaleh, Mohammed A. Jailani, Dal'ia A. Murshid, and Shaima H. Aljeeb.

\section{Competing Interests Statement}

The authors declare that there are no competing or potential conflicts of interest.

\section{References}

Abdel rahman, A. G., Al hashimi, B. N., Al hiji, N. K., \& Al-abbad, Z. (2013). Stress among medical Saudi students at College of Medicine, King Faisal University. Journal of Preventive Medicine and Hygiene, 54(4), 195-199.

Abdulghani, H. M., AlKanhal, A. A., Mahmoud, E. S., Ponnamperuma, G. G., \& Alfaris, E. A. (2011). Stress and Its Effects on Medical Students: A Cross-sectional Study at a College of Medicine in Saudi Arabia. Journal of Health, Population, and Nutrition, 29(5), 516-522. https://doi.org/10.3329/jhpn.v29i5.8906

Almalki, S. A., A. I. Almojali, A. S. Alothman, E. M. Masuadi, and M. K. Alaqeel. (2017). Burnout and its association with extracurricular activities among medical students in Saudi Arabia. Int J Med Educ, 8, 144-50. https://doi.org/10.5116/ijme.58e3.ca8a

Al Ubaidi, B. A. (2015). How to reduce your burnout. J Bahrain Med Soc, 26(1), 56-63.

Almeida, G. D., Souza, H. R., Almeida, B. D., \& Almeida, G. H. (2016). The prevalence of burnout syndrome in medical students (P. C. Almeida, Ed.). Archives of Clinical Psychiatry (São Paulo), 43(1), 6-10. https://doi.org/10.1590/0101-60830000000072

Bera, T., Mandal, A., Bhattacharya, S., Biswas, N. M., Ghosh, A., \& Bera, S. (2013). Burn Out Among Medical Students - A Study Across Three Medical Colleges in Eastern India. Indian Medical Gazette. September 2013.

Bianchin, M., \& Angrilli, A. (2012). Gender differences in emotional responses: A psychophysiological study. Physiology \& Behavior, 105(4), 925-932. https://doi.org/10.1016/j.physbeh.2011.10.031

dos Santos Boni, R. A., Paiva, C. E., de Oliveira, M. A., Lucchetti, G., Fregnani, J. H. T. G., \& Paiva, B. S. R. 
(2018). Burnout among medical students during the first years of undergraduate school: Prevalence and associated factors. PloS one, 13(3), e0191746. https://doi.org/10.1371/journal.pone.0191746

Cecil, J., McHale, C., Hart, J., \& Laidlaw, A. (2014). Behaviour and burnout in medical students. Medical Education Online, 19, 10.3402/meo.v19.25209. https://doi.org/10.3402/meo.v19.25209

Chandan, N., \& Mayur, S. S. (2017). Assessment of Stress and Burnout among Medical Graduates using PSS-14 and MBI-SS scales. National Journal of Research in Community Medicine, 6(1), 44-49.

Chigerwe, M., Boudreaux, K. A., \& Ilkiw, J. E. (2014). Assessment of burnout in veterinary medical students using the Maslach Burnout Inventory-Educational Survey: a survey during two semesters. BMC Medical Education, 14, 255. https://doi.org/10.1186/s12909-014-0255-4

Chunming, W. M., Harrison, R., MacIntyre, R., Travaglia, J., \& Balasooriya, C. (2017). Burnout in medical students: a systematic review of experiences in Chinese medical schools. BMC medical education, 17(1), 217. https://doi.org/10.1186/s12909-017-1064-3

Dafaalla, M., Bashir, S., Farah, A., \& Abdalrahman, I. (2016). Depression, Anxiety, and Stress in Sudanese Medical Students: A Cross Sectional Study on Role of Quality of Life and Social Support. American Journal of Educational Research, 26(13), 937-942. http://doi:10.12691/education-4-13-4.

De Oliva Costa, E. F., Santos, S. A., de Abreu Santos, A. T. R., de Melo, E. V., \& de Andrade, T. M. (2012). Burnout Syndrome and associated factors among medical students: a cross-sectional study. Clinics, 67(6), 573-579. https://doi.org/10.6061/clinics/2012(06)05

Dyrbye, L., \& Shanafelt, T. (2015). A narrative review on burnout experienced by medical students and residents. Medical Education, 50(1), 132-149. https://doi.org/10.1111/medu.12927

El-masry, R., Ghreiz, S. M., Helal, R. M., Audeh, A. M., \& Shams, T. (2013). Ibnosina J Med BS, 5(4), 179-188. https://doi.org/10.4103/1947-489X.210543

Eva, E. O., Islam, M. Z., Mosaddek, A. S. M., Rahman, M. F., Rozario, R. J., Iftekhar, A. F. M. H., ... Haque, M. (2015). Prevalence of stress among medical students: a comparative study between public and private medical schools in Bangladesh. BMC Research Notes, 8, 327. https://doi.org/10.1186/s13104-015-1295-5

Fares, J., Al Tabosh, H., Saadeddin, Z., El Mouhayyar, C., \& Aridi, H. (2016). Stress, Burnout and Coping Strategies in Preclinical Medical Students. North American Journal of Medical Sciences, 8(2), 75-81. https://doi.org/10.4103/1947-2714.177299

Fares, J., Ayoub, F., \& Fares, Y. (2015). The psychological attitude of patients toward health practitioners in Lebanon. North American Journal of Medical Sciences, $7(10), 452$. https://doi.org/10.4103/1947-2714.168663

Fawzy, M., \& Hamed, S. A. (2017). Prevalence of psychological stress, depression and anxiety among medical students in Egypt. Psychiatry Research, 255, 186-194. https://doi.org/10.1016/j.psychres.2017.05.027

Galán, F., Ríos-Santos, J. V., Polo, J., Rios-Carrasco, B., \& Bullón, P. (2014). Burnout, depression and suicidal ideation in dental students. Medicina Oral, Patología Oral Y Cirugía Bucal, 19(3), e206-e211. https://doi.org/10.4317/medoral.19281

Gazzaz, Z. J., Baig, M., Al Alhendi, B. S. M., Al Suliman, M. M. O., Al Alhendi, A. S., Al-Grad, M. S. H., \& Qurayshah, M. A. A. (2018). Perceived stress, reasons for and sources of stress among medical students at Rabigh Medical College, King Abdulaziz University, Jeddah, Saudi Arabia. BMC Medical Education, 18, 29. https://doi.org/10.1186/s12909-018-1133-2

Guthrie, E., Black, D., Bagalkote, H., Shaw, C., Campbell, M., \& Creed, F. (1998). Psychological stress and burnout in medical students: a five-year prospective longitudinal study. Journal of the Royal Society of Medicine, 91(5), 237-243. https://doi.org/10.1177/014107689809100502

Heinen, I., Bullinger, M., \& Kocalevent, R.-D. (2017). Perceived stress in first year medical students - associations with personal resources and emotional distress. BMC Medical Education, 17, 4. https://doi.org/10.1186/s12909-016-0841-8

Ibrahim, N., Dania, A. K., Lamis, E. K., Ahd, A. H., \& Asali, D. (2013). Prevalence and predictors of anxiety and depression among female medical students in King Abdulaziz University, Jeddah, Saudi Arabia. Iranian journal of public health, 42(7), 726.

Ishak, W., Nikravesh, R., Lederer, S., Ogunyemi, D., \& Bernstein, C. (2013). Burnout in medical students: A 
systematic review. The Clinical Teacher, 10(4), 242-5. https://doi.org/10.1111/tct.12014

Konjengbam, S., Laishram, J., Singh, B., \& Elangbam, V. (2015). Psychological morbidity among undergraduate medical students. Indian Journal of Public Health, 59(1), 65. https://doi.org/10.4103/0019-557X.152872

Kulsoom, B., \& Afsar, N. A. (2015). Stress, anxiety, and depression among medical students in a multiethnic setting. Neuropsychiatric Disease and Treatment, 11, 1713-1722. https://doi.org/10.2147/NDT.S83577

Ludwig, A. B., Burton, W., Weingarten, J., Milan, F., Myers, D. C., \& Kligler, B. (2015). Depression and stress amongst undergraduate medical students. BMC Medical Education, 15(1). https://doi.org/10.1186/s12909-015-0425-z

Muzafar, Y., Khan, H. H., Ashraf, H., Hussain, W., Sajid, H., Tahir, M., ... Ahmad, W. (2015). Burnout and its Associated Factors in Medical Students of Lahore, Pakistan. Cureus, 7(11), e390. https://doi.org/10.7759/cureus.390

Niemi, P., \& Vainiomäki, P. (2006). Medical students' distress - quality, continuity and gender differences during a six-year medical programme. Medical Teacher, 28(2), 136-141. https://doi.org/10.1080/01421590600607088

Pagnin, D., \& de Queiroz, V. (2015). Influence of burnout and sleep difficulties on the quality of life among medical students. Springer Plus, 4, 676. https://doi.org/10.1186/s40064-015-1477-6

Paro, H. B. M. S., Silveira, P. S. P., Perotta, B., Gannam, S., Enns, S. C., Giaxa, R. R. B., \& Tempski, P. Z. (2014). Empathy among Medical Students: Is There a Relation with Quality of Life and Burnout? PLoS ONE, 9(4), e94133. https://doi.org/10.1371/journal.pone.0094133

Schaufeli, W. B., Bakker, A. B., Hoogduin, K., Schaap, C., \& Kladler, A. (2001). On the clinical validity of the Maslach Burnout Inventory and the Burnout Measure. Psychology \& health, 16(5), 565-582. https://doi.org/10.1080/08870440108405527

Seo, J.-H., Kim, H. J., Kim, B.-J., Lee, S.-J., \& Bae, H. (2015). Educational and Relational Stressors Associated with Burnout in Korean Medical Students. Psychiatry Investigation, 12(4), 451-458. https://doi.org/10.4306/pi.2015.12.4.451

Siddiqui, M. A., Jahan, F., \& Mitwally, M. (2016). Perception of Stress, Anxiety, Depression and Coping Strategies among Medical Students at Oman Medical College. World Family Medicine Journal/Middle East Journal of Family Medicine, 14(7), 16-23. https://doi.org/10.5742/MEWFM.2016.92856

Sohail, N. (2013). Stress and academic performance among medical students. J Coll Physicians Surg Pak., 23(1), 67-71. http://doi:01.2013/JCPSP.6771.

Solanky, P., Desai, B., Kavishwar, A., \& Kantharia, S. (2012). Study of psychological stress among undergraduate medical students of government medical college, Surat. International Journal of Medical Science and Public Health, 1(2), 38. https://doi.org/10.5455/ijmsph.2012.1.38-42

Sreedevi, A., Rao, G., Bharath, P., Reddy, K., Parigala, R., Pappu, S. . . Parem, S. (2016). Study on stress among first-year medical students of Kurnool Medical College, Kurnool. International Journal of Medical Science and Public Health, 5(5), 852. https://doi.org/10.5455/ijmsph.2016.31082015141

Supe, A. (1998). A study of stress in medical students at Seth G.S. Medical College. J Postgrad Med, 44(1), 1-6. Retrieved January/March, 1998.

Vinodh, R. S., \& Pradeep, C. (2016). Evaluation of Burnout Syndrome in Medical Students. J Pharm Chem Biol Sci, 4(2), 299-306. Retrieved June/August, 2016.

Youssef, F. F. (2016). Medical Student Stress, Burnout and Depression in Trinidad and Tobago. Academic Psychiatry, 40(1), 69-75. https://doi.org/10.1007/s40596-015-0468-9

\section{Copyrights}

Copyright for this article is retained by the author(s), with first publication rights granted to the journal.

This is an open-access article distributed under the terms and conditions of the Creative Commons Attribution license (http://creativecommons.org/licenses/by/4.0/). 